\title{
Creating a Psychologically Comfortable Educational Environment as a Factor of Successful Academic Program Acquisition by Technical University Students
}

\author{
Vsevolod V. Andreev" ${ }^{1, *}$, Lidia N. Vasilieva², Vladimir I. Gorbunov², Olga K. Evdokimova ${ }^{3}$, \\ Nataliia N. Timofeeva ${ }^{4}$
}

\footnotetext{
${ }^{1}$ Department of Heat Power Setups, Faculty of Energy and Electrical Engineering, Chuvash State University, Cheboksary, Russia ${ }^{2}$ Department of Automation and Control in Technical Systems, Faculty of Radio Electronics and Automation, Chuvash State University, Cheboksary, Russia

${ }^{3}$ Department of Russian Language and Literature, Faculty of Russian and Chuvash Philology and Journalism, Chuvash State University, Cheboksary, Russia

${ }^{4}$ Department of Higher Mathematics and Theoretical Mechanics named after S.F. Saikin, Chuvash State University, Cheboksary, Russia
}

Received June 25, 2020; Revised August 11, 2020; Accepted August 25, 2020

\section{Cite This Paper in the following Citation Styles}

(a): [1] Vsevolod V. Andreev, Lidia N. Vasilieva, Vladimir I. Gorbunov, Olga K. Evdokimova, Nataliia N. Timofeeva , "Creating a Psychologically Comfortable Educational Environment as a Factor of Successful Academic Program Acquisition by Technical University Students," Universal Journal of Educational Research, Vol. 8, No. 10, pp. 4707 4715, 2020. DOI: 10.13189/ujer.2020.081040.

(b): Vsevolod V. Andreev, Lidia N. Vasilieva, Vladimir I. Gorbunov, Olga K. Evdokimova, Nataliia N. Timofeeva (2020). Creating a Psychologically Comfortable Educational Environment as a Factor of Successful Academic Program Acquisition by Technical University Students. Universal Journal of Educational Research, 8(10), 4707 - 4715. DOI: 10.13189/ujer.2020.081040.

Copyright $\bigcirc 2020$ by authors, all rights reserved. Authors agree that this article remains permanently open access under the terms of the Creative Commons Attribution License 4.0 International License

\begin{abstract}
The paper analyses two psychological and pedagogical concepts, namely, the need- informational theory of emotions and the self-determination theory. These theories are focused on the priority of the students' activity. Thus, the educational process should create opportunities for a student to predict a result of his/her activity and to give it a predominant status. It is also necessary to develop an environment intended to demonstrate independence and creativity, focus on positive emotions and a need for self-respect, as well as to maintain an acceptable level of anxiety. The target criterion is to provide a psychologically comfortable educational environment. From this perspective, we described and analysed our experience of a transdisciplinary approach to teaching the Russian Language and Business Communication course, as well as to the blended learning technique for teaching the Informatics and Information Technology in Radioelectronics and the Mathematical Analysis courses. The former case demonstrated a qualitative effect of mini-research tasks performed by the students. As for the latter case, we carried out several
\end{abstract}

experiments that detected a significant difference of the examination scores with higher grades and lower anxiety level in the experimental groups (as compared to the control ones).

Keywords Comfortable Educational Environment, Blended Learning, Anxiety Level, Positive Emotions, The Need- Informational Theory of Emotions, The Self-determination Theory, Students' Activity, State-Trait Anxiety Inventory

\section{Introduction}

Russian institutions for higher technical education treat the development of humanitarian, cultural skills and moral education of a future technical specialist by a rather residual principle. This is one of the reasons why the students demonstrate weaker figurative thinking and, therefore, lower personal creative potential. Moreover, 
they show some difficulties with knowledge summarizing and application to allied disciplines, and treat their learning outcome with indifference, which results in lower cognitive activity (Andreev et al. 2020a; Evdokimova et al. 2019; Gorbunov et al. 2019). The traditional university education was replaced by rationalism and pragmatism (Evdokimova et al. 2017). All these undermine a graduate's social engagement and development of his/her personal and communicative characteristics representing the vulnerability of an engineering student (Gorbunov et al. 2017; Gorbunov and Evdokimova 2018).

Laws of nature and social development require natural extrapolation and succession of the process rather than the spontaneous introduction of various models (Andreev et al. 2017; Andreev et al. 2019). In this context, the issue is to transform a whole system of higher technical education according to the challenges of the time that require an enhanced professional component providing successful self-realization of a young professional in the labour market. However, a place and importance of the humanities should be specified as a base to learn the non-humanities to develop creative capacities and to form personal qualities of future tech intellectuals.

The research problem of this study is to find theoretical concepts and to develop practical recommendations intended to create a psychologically comfortable environment for the students' learning to improve educational process quality by systematic usage of educational information and communication technologies (ICT).

The research objective is to analyse, to summarize and to develop advanced educational strategies in order to provide a psychologically comfortable educational environment as a primary factor of successful academic program learning by engineering students in a higher education institution.

\section{Literature Review}

The best current learning practices and technologies encourage a student to reflect upon his/her own or common point of view. Also, they give the students a reason to acquire new knowledge in an area where they posture themselves as "creative minds" both developing something new and feeling responsible for the decisions made. A teacher (i.e., a key link in the development of a person and society) plays a leading role in the development and introduction of these methods and technologies in the educational process. Thus, the author of one of famous papers (Shim 2008) studied a teacher's role from the perspective of synthesizing and comparing 4 major approaches to teaching comprehension stated by Plato, Confucius, Buber and Freire. According to Plato, teaching is guidance to acquire objective knowledge through a well-reasoned analysis of causes. As explained by Confucius, learning is self-cultivation. Buber thought that building a relationship with a pupil is the most important ability of a teacher. Freire gave priority to the criticism of a studied issue. Another researcher (Zhao 2013) concluded that the Confucian educational concept and traditional critical pedagogics have 4 common features such as peer tuition, integration of theory and practice, reflection in teaching and learning and a democratic educational goal.

Perez-Prado and Thirunarayanan (2002) emphasize several necessary aspects of the educational process (i.e., interaction, collaborative learning and an emotional component). Gilbert and Driscoll (2002) describe several necessary conditions to effectively support learning. These conditions include a current collective common goal of a learning community, promoting the cooperation and involvement in the society in order to discuss and to promote various points of view; to provide personal student's participation in a term paper selection and team decision-making in the context of educational self-stimulation; to achieve an integrated kit of processing tools dealing with the archiving of the community's work product; to facilitate communication.

The study of Chen et al. (2020) is worth noticing. It detected that the students who had been experiencing peer assessment and commenting demonstrated better academic results coupled with higher motivation to the result achievement.

Significant learning support and the ability to detect a low-skilled student are overriding factors that determine the efficiency of a Virtual Reality Training System (VRTS) (Santamaría-Bonfil et al. 2020).

Liu et al. (2020) represented a systematic analysis of 131 articles dealing with the acceptance of innovative educational technologies by teachers. The data testify that the acceptance of innovative technologies is a complicated process influenced by educational technologies, teaching environment, context and strategies.

A study of Duryagina (2019) was devoted to the students' subjective comfort during an examination session. It determines general academic failure and the presence of examination sessions in a higher education institution to be the main stress factors for the students. The need to analyse and to summarize plenty of information on various academic subjects in the face of time pressure is the source of the student stressful overload. As a result, the researchers found out that many students perceive an exam as a "refined torture" performed by a teacher (Imamgalieva 2017).

In the light of the intensive development and active introduction of ICT into everyday life, the teaching methods developing a student's ability to independently analyse the multidimensional information necessary for the acquisition and generation of new knowledge are of considerable value. In this regard, a concept of Technological Pedagogical Content Knowledge (TPACK) was formulated (see, for example, Jang and Chen 2010; Yalçın and Yayla 2016). It is widely used in teaching. At the same time, Sanders and George (2017) concluded that the initial perception of the ICT role and capabilities in the 
educational process was too audacious. In particular, for most students, ICT has not yet become a tool that contributes to the formation of a young creative specialist (Andreev et al. 2020; Vasilieva et al. 2020). Therefore, ICT implementation in an educational process requires setting achievable goals based on the relevance of the educational contexts. For example, an idea of tight integration between STEM technology and TPACK is noteworthy (Iswadi et al. 2020).

Pedagogical paradigms are classified in accordance with theories of personality development (i.e., behaviourism, psychoanalysis, cognitivism, positivism). All these theories have a consensus of opinion that human development is determined by heredity and environment. Although all of them consider the criterion of utility and formation of theoretical thinking as a priority, little attention is given to the knowledge integrity. Humanistic psychology (Maslow 1943; Clippinger 1973) is an alternative to this approach. On the viewpoint of Humanistic psychology a student is considered as a whole person. The emphasis is on his/her own activity and an innate personal need for self-actualization instead of external effects.

The analysis of psychological and pedagogical paradigms shows that those based on a compromise between different points of view have the most noticeable effect. We believe that the need- informational theory of emotions (Simonov and Yershov 1991; Simonov 2001) allows for a certain compromise between the sociocentric and humanistic ideas. It includes several basic needs. The need for competence originates from imitative and game unconditioned reflexes and manifests itself in the desire to gain experience for the future, without its current pragmatic significance. According to Pavlov, a "reflex of freedom" is a prototype of will as a basic need to overcome obstacles (Pavlov 1973). Creative intuition is not controlled by consciousness and will. It supports the most urgent need of an individual. In this regard, the fact that training and self-development are only possible with sufficient support of reciprocal activity of a person is extremely important for pedagogics. Motivation to activity is ensured by appropriate initial training that is exclusively based on meeting the needs for competence, knowledge and creation. Unfortunately, pedagogics underestimates the role of the learning outcome strength and imitation activities that form such strength through practical and play classes. To promote creative intuition along with the interaction of rational and non-reflexive mental spheres, the current educational activity should be based on positive emotions. Also, a subject should perceive it as a predominant one.

The theory of self-determination is a popular theory of personal motivation that identifies three basic human needs (i.e., autonomy, competence and interaction with other people). The needs for competence and self-determination are the basis of a choice determining the experience gaining activities. It does not require any external requirements or reinforcements. These two needs determine internal motivation based on emotions and information from the environment and personal memory. Any conflicts between actual needs are resolved by will (i.e., an ability to make a conscious choice of a behavioural determinant) (Deci and Ryan 2008).

Both mentioned theories are focused on close basic needs of a person. They put emotions determined by information received from the environment and personal memory at the top of personal priorities. Both of them do not ignore the role of social needs considering will as a mandatory psychological mechanism. According to these theories, an external educational impact on students should be complemented by their own activity.

A scientific literature review on the topic of our research shows that in pedagogical science and education practice particular importance is attached to the motivation factor, the creation of conditions for the creative activity of students and for responsibility manifestation for the decisions made. In many papers the methods of educational interaction of trainees with each other, methods of reducing the level of stress caused by an intense training load, and etc. have been studied. However, despite broad-spectrum researches, the development of psychologically comfortable educational environment was not considered as a predominant task.

\section{Materials and Methods}

The methodological basis of this study is the statements of the need-information theory of the behaviour organization and the theory of self-determination. Our comparative analysis, in addition to the well-known differences between them, also revealed common between them, which consists in a high assessment of the role of emotional-volitional qualities of the individual and social needs. Among the latter in this paper, we focus on the need for self-respect. It is known from psychology that in cases when problem situations difficulty exceeds the student's capabilities, to maintain emotional balance and self-respect, the brain subconsciously uses the techniques for protection of ideas about itself. This distortion of reality, satisfying the need for self-esteem, reduces anxiety, supports confidence sense, self-esteem and motivation for action. The teacher pays attention to the student's need for self-respect and to the person's anxiety, combined with the idea of learning on the background of positive emotions, we called a factor of creation of psychologically comfortable conditions for students. We propose to consider this factor as a kind of objective function (by analogy with the accepted in mathematics). We put forward a hypothesis that the implementation of this factor in educational methods contributes to an increase in their effectiveness, since, in a first approximation, to the teacher is offered specific items from the subtest for situational anxiety as criteria. In our opinion, the hypothesis is 
confirmed by the experience described below of applying of the transdisciplinary approach in the subject "Russian language and business communications" and the implementation of blended learning in the teaching of computer science subject.

Materials and methods are defined by the need for a comprehensive pedagogical study. We used theoretical analysis, observation, testing, pedagogical experiment, data processing methods and testing of a statistical hypothesis. To summarize empirical results, we used a systemic approach. Mann-Whitney test was applied to statistical processing of the academic records in the experimental and control groups. The Spielberger State-Trait Anxiety Inventory (Sydeman 2018) adopted in Russian by Hanin (Hanin and Spielberger 1981) was used to measure the anxiety level.

The experimental base is represented by students of the Radioelectronics and Automatics Faculty and the Informatics and Computer Engineering Faculty of the Chuvash State University.

\section{Results and Discussion}

Since a study case should tug at heartstrings and be understandable for the mind, the educational environment should be developed the way enabling the students to predict an outcome of their activity and to give it a significant status; to demonstrate independence and creation; to involve emotional and volitional personal spheres with a focus on positive emotions and interest; to support an acceptable need for self-respect and to keep an acceptable level of anxiety. To summarise, let us consider the provision of a psychologically comfortable personal educational environment as a choice criterion limited by both technical support of the educational process and an initial student's training level (available knowledge, ability to work independently and creatively). Given the choice criterion, we will further describe the experience of applying the transdisciplinary approach to the Russian Language and Business Communication course (mini-research tasks) and to the implementation of the blended learning technique in informatics.

It is known that the transdisciplinary approach is intended to combine the knowledge that is different by content and methods. The approach meets the ideas of integrity coupled with the integration of natural, social and mental activity laws (Bernstein 2015). Formerly, we proposed an extended understanding of the transdisciplinarity idea in the educational process, including the integration of all educational components (i.e., training forms, behavioural aspects, more effective contact (formal and informal) between teachers of different subjects) (Andreev et al. 2020a). Such integration is associated with an increased focus on independent educational activities (in particular, to research, which is an important tool to increase a student's internal motivation), the predominance of relevant activity, combination of a student's self-management and management by student both by a teacher and with the help of technical training tools.

Hence, mini-research tasks (i.e., creative and business letter rule authoring, publicist/training text analysis [abstract and key words]) were evaluated in the frame of the Russian Language and Business Communication course. Particular attention should be given to several tasks entailing a combination of analytical and creative approaches. Namely, these tasks represent the creation of an advertising copy describing a student's faculty or future profession, a job-seeker self-introduction both orally and in writing, as well as a cinquain on a set theme. It should be emphasized that an advertising copy, a self-introduction and a cinquain are quite schematic. The difficulty is to fill up a ready-to-use scheme with unique content in the frames of these tasks. Among other things, these tasks train a student to move beyond a conventional scheme. Thus, we can determine whether he/she can think creatively, inventively and innovatively, and find out the degree of independence from the existing stereotypes. In this view, a cinquain (i.e., 5 lines with a limited number of words) is a demonstrative method. Its development promotes knowledge systematization. This forms a summarizing ability - one of the major skills of any professional. As an example, the students of the Informatics and Computer Engineering Faculty noted that covering several topics (such as Internet, Experience, and Creation) in a concise unconventional way led to re-discovery of the Internet advantages and disadvantages closely connected with their future profession. Dealing with these tasks requires individual comprehension of the topic, creativity, appropriate vocabulary and stylistics. The key is that a student can correct his/her vision of a future profession, as well as to recalculate its pros and contras. This means having an entirely fresh angle on the issue or an outside point of view when a subjective point of view organically becomes an objective one. Therefore, this gives a student additional confidence in the correctness of his or her choice.

Apart from general knowledge, these tasks require not only some specific knowledge of several disciplines but also stable skills of their simultaneous use. Just at that spot a need for a transdisciplinary approach arises. This represents a combination of special knowledge, communicative skills, verbal persuasiveness and personal student's qualities (i.e., positive thinking, benevolence and reasonable self-esteem). Thus, a transdisciplinary connection between the humanities and the non-humanities that develop cross-competencies shared by the disciplinary group works towards the result - the formation of a professional being an expert in his/her area and ready to meaningful cooperation beyond its borders.

We applied the Face-to-Face Driver blended learning (Cuesta Medina 2018) characterized by a leading role of classroom activities (80\%) and an underpart of e-learning 
(20\%). The experiment aimed to evaluate the efficiency of our blended learning method counted 37 first-year students and 39 second-year students of Radioelectronics and Automatics Faculty of the Chuvash State University, as participants. They studied the Informatics and Information Technology in Radioelectronics course taught by a Candidate of Pedagogical Sciences. Also, 46 first-year students and 40 second-year students of the Informatics and Computer Engineering Faculty of the Chuvash State University, studying the Mathematical Analysis course taught by a Candidate of Physical and Mathematical Sciences participated in the experiment. The experimental groups experienced the blended learning technique, while the control groups studied the same courses in a conventional way a year earlier.

Stage succession was as follows. A teacher uploads a topic in an e-learning system (ELS). A student learns it in any convenient environment (e.g., at home, at the university, outdoors etc.) in a random fashion and at his/her own pace. Then, a student passes a test in the ELS independently. He/she can communicate with peers and the teacher (as agreed). Group communication was implemented through a forum, a wiki and a chat. In turn, individual communication represented a file exchange. Constantly being in contact with students both in the classroom and online environments, the teachers were focused on managing every student's individual activities, as well as their mutual assistance.

A final class for the topic was carried out using the Moodle ELS in a computer lab where the teacher acted as a consultant directly. The self-directed learning outcome was evaluated by a test. The test question difficulty was assessed with a weighting coefficient. If an answer was correct, a student went on to the next question, and his/her current rating increased by a question weight value. If an answer was wrong, a student was invited to review the information and to answer the question again. His/her current rating increased by a lower value. Herewith, there were three following possible cases.

1. A student answered the test questions correctly, or his/her mistake number was small. Therefore, he/she completed the test independently and got high rating points (18.9\% and $19.6 \%$ at the Radioelectronics and Automatics Faculty, and Informatics and Computer Engineering Faculty, respectively).

2. If a mistake was repeated, the students were invited to cooperate in groups (2 or 3 members) with similar training progress. A teacher observed the fulfillment of the homogeneity principle. Direct tips were unadvisory. Cooperative cross-beneficial activity concerning the transformation of the teaching information into knowledge was detected (54\% and $47.8 \%$ in the Radioelectronics and Automatics Faculty, and Informatics and Computer Engineering Faculty, respectively).

3. If the group had any issues, a teacher assisted it choosing the moment and extent of assistance as a matter of his/her experience (27.1\% and $32.6 \%$ in the Radioelectronics and Automatics Faculty, and Informatics and Computer Engineering Faculty, respectively).

Despite increased leaning time in two latter cases, we provide a psychologically comfortable educational environment associated with positive motions along with acceptable levels of anxiety and self-esteem.

To be sure, due to increased labour inputs of a teacher, the experiment is doomed to success. However, with respect to the paper subject, a reason for the effect is of importance. According to recommendations of the motivational theories mentioned above, a teacher's assistance was primarily intended to encourage a student's activity. In this view, we created an educational environment to predict activity outcome, as well as to demonstrate the independence and creativity of a student. As per the choice criterion of the paper (i.e., to provide a psychologically comfortable educational environment for a student), the teachers paid attention to the fact that a student should understand a whole issue qualitatively with further formalistic quantitative transformations. In the meaning of transdisciplinarity, the teachers shared their experience relating to the training content and learning methods. Along with this, they pointed out the training metaphor. That is why appropriate models were used in LabVIEW software.

Mann-Whitney test was applied to the statistical processing of the exam results (Mann and Whitney 1947). We developed several hypotheses, namely $\mathrm{H}_{0}$ (there is no significant difference between control and experimental groups) and $\mathrm{H}_{1}$ (there is a significant difference between control and experimental groups). At the given significance level $\alpha$ the main hypothesis $\mathrm{H}_{0}$ is accepted if the criterion value $U_{1}$ is greater than the critical value $U_{\mathrm{cr}}$ (i.e., $U>U_{\mathrm{cr}}$ ) determined by the table of Critical Values for the Mann - Whitney U-Test. Detailed information on the application of the criterion can also be found on the Internet. For our study see empirical values of control and experimental groups in Table 1.

Table 1. Performance analysis for the control and experimental student groups ( $n_{1}$ and $n_{2}$ are the number of students in the control and experimental groups, respectively).

\begin{tabular}{|c|c|}
\hline Radioelectronics and Automatics Faculty & Informatics and Computer Engineering Faculty \\
\hline$n_{1}=39, n_{2}=37$. & $n_{1}=40, n_{2}=46 \cdot$ \\
$U=383$. & $U=460$. \\
For the significance level $\alpha=0,05$ we have $U_{\mathrm{cr}}=562 \cdot$ & $\begin{array}{c}\text { For the significance level } \alpha=0,05 \text { we have } U_{\mathrm{cr}}=729 \cdot \\
\text { Therefore, } 383<562\left(U<U_{\mathrm{cr}}\right) .\end{array}$ \\
\hline
\end{tabular}


According to Table 1, the case $U<U_{\text {cr }}$ is observed in both faculties. Thus, the $\mathrm{H}_{0}$ hypothesis is rejected. In other words, student performance is significantly higher in the experimental groups than in the control ones. In Table 2 the initial data on students progress in control and experimental groups are represented.

Table 2. Indicators of students progress in control and experimental groups.

\begin{tabular}{|c|c|c|c|c|}
\hline \multirow{2}{*}{$\begin{array}{c}\text { Index } \\
\text { numbers }\end{array}$} & \multicolumn{2}{|c|}{ Radioelectronics and Automatics Faculty } & \multicolumn{2}{|c|}{ Informatics and Computer Engineering Faculty } \\
\hline & Control group & Experimental group & Control group & Experimental group \\
\hline 1 & 4 & 3 & 4 & 5 \\
\hline 2 & 3 & 4 & 3 & 4 \\
\hline 3 & 4 & 4 & 3 & 4 \\
\hline 4 & 3 & 5 & 3 & 5 \\
\hline 5 & 4 & 5 & 3 & 5 \\
\hline 6 & 4 & 3 & 4 & 4 \\
\hline 7 & 3 & 3 & 5 & 4 \\
\hline 8 & 3 & 4 & 5 & 3 \\
\hline 9 & 4 & 5 & 3 & 3 \\
\hline 10 & 4 & 4 & 3 & 5 \\
\hline 11 & 3 & 5 & 3 & 3 \\
\hline 12 & 4 & 4 & 3 & 4 \\
\hline 13 & 3 & 4 & 3 & 4 \\
\hline 14 & 3 & 4 & 3 & 3 \\
\hline 15 & 3 & 5 & 3 & 3 \\
\hline 16 & 4 & 4 & 3 & 4 \\
\hline 17 & 3 & 3 & 3 & 4 \\
\hline 18 & 3 & 5 & 3 & 3 \\
\hline 19 & 4 & 4 & 4 & 4 \\
\hline 20 & 5 & 4 & 3 & 5 \\
\hline 21 & 3 & 4 & 5 & 5 \\
\hline 22 & 3 & 4 & 3 & 4 \\
\hline 23 & 4 & 4 & 3 & 3 \\
\hline 24 & 3 & 5 & 4 & 4 \\
\hline 25 & 3 & 4 & 4 & 4 \\
\hline 26 & 4 & 4 & 3 & 4 \\
\hline 27 & 4 & 5 & 3 & 3 \\
\hline 28 & 5 & 4 & 3 & 4 \\
\hline 29 & 3 & 4 & 3 & 5 \\
\hline 30 & 3 & 4 & 4 & 3 \\
\hline 31 & 3 & 5 & 3 & 4 \\
\hline 32 & 5 & 5 & 3 & 4 \\
\hline 33 & 4 & 3 & 3 & 5 \\
\hline 34 & 3 & 4 & 3 & 4 \\
\hline 35 & 3 & 5 & 3 & 5 \\
\hline 36 & 3 & 5 & 3 & 4 \\
\hline 37 & 4 & 4 & 3 & 3 \\
\hline 38 & 4 & - & 5 & 4 \\
\hline 39 & 4 & - & 3 & 5 \\
\hline 40 & - & - & 3 & 5 \\
\hline 41 & - & - & - & 3 \\
\hline 42 & - & - & - & 4 \\
\hline 43 & - & - & - & 4 \\
\hline 44 & - & - & - & 4 \\
\hline 45 & - & - & - & 4 \\
\hline 46 & - & - & - & 5 \\
\hline
\end{tabular}


According to the observation results, in experimental groups educational process becomes more interesting, personally significant and carry out on a positive emotional background, in more comfortable conditions for students' educational activity. These qualitative conclusions were confirmed quantitatively. The experimental and control students (Radioelectronics and Automatics Faculty) were faced with the Spielberger State-Trait Anxiety Inventory (Sydeman 2018) adapted to Russian by Hanin (Hanin and Spielberger 1981). With respect to the test subject, it was focused on the state anxiety subtest only. High anxiety level ( $\geq 45$ scores) means overpressure, discomfort, concern and nervousness. In turn, low level (20-30 scores) implies normal condition; however, it is desirable for a person to show more emotional involvement in what is happening and not to restrain his/her feelings. The test items were uploaded to Google Forms (i.e., an online service intended for creation of feedback forms, online testing and questionnaires). As per a key for the test, total scores of every student were taken as input data. The results are presented in Table 3.

According to Table 3, firstly, the experimental group demonstrates lower anxiety score. Secondly, despite similar student percentage detected by the test at all the levels, the experimental group includes a lower percentage of students with high anxiety level than the control one. We also analysed the test outcomes in by certain questions.
Table 3. The results of evaluation of situational anxiety of students.

\begin{tabular}{|c|c|c|}
\hline Anxiety level & $\begin{array}{c}\text { Experimental group } \\
\text { (37 person) }\end{array}$ & $\begin{array}{c}\text { Control group (70 } \\
\text { person) }\end{array}$ \\
\hline Low & $3(8 \%)$ & $6(9 \%)$ \\
\hline Moderate & $32(87 \%)$ & $59(84 \%)$ \\
\hline High & $2(5 \%)$ & $5(7 \%)$ \\
\hline Mean test score & 35,14 & 36,87 \\
\hline
\end{tabular}

Table 4 contains the test questions on situational anxiety, according to which the number of students and their percentage in the experimental and control groups are most different.

This refers to 4 optimistic questions $(1,2,5,11)$ and 1 pessimistic question (7) among 20 questions of the test. Among the 4 possible answers to each question, one grade denies a question (1 - "It's not like that at all"). Three other grades confirm it with different extent (2 - "Perhaps so"; 3 - "It's right"; 4 - "It's absolutely right"). For example, question 1, which denies anxiety, was answered in the affirmative by $86 \%$ of students in the experimental group and $79 \%$ of students in the control group. To question 7 , confirming the state of anxiety, a larger percentage of affirmative answers in the control group. Students clearly understand that the test questions assess their current emotional state, and not psychological qualities in general in life. Thus, the results of analysis of answers to test questions also indicate less anxiety of students in the experimental group.

Table 4. Test answers evaluation results

\begin{tabular}{|c|c|c|c|c|}
\hline \multirow[b]{2}{*}{ Questions } & \multicolumn{2}{|c|}{ Experimental group } & \multicolumn{2}{|c|}{ Control group } \\
\hline & $\begin{array}{c}\text { Grade } 1 \\
\text { "It's not like that at all" }\end{array}$ & Grades 2, 3, 4 & $\begin{array}{c}\text { Grade } 1 \\
\text { "It's not like that at all" }\end{array}$ & Grades 2, 3, 4 \\
\hline 1. I'm calm & $5(14 \%)$ & $32(86 \%)$ & $15(21 \%)$ & $55(79 \%)$ \\
\hline 2. Nothing threatens me & $10(27 \%)$ & 27 (73\%) & 22 (31\%) & 48 (69\%) \\
\hline 5. I feel free & $4(15 \%)$ & $33(85 \%)$ & $12(17 \%)$ & $58(83 \%)$ \\
\hline 7. I'm worried about possible setbacks & 19 (51\%) & $18(49 \%)$ & $30(42 \%)$ & $40(58 \%)$ \\
\hline 11. I'm confident & $5(14 \%)$ & $32(86 \%)$ & $12(17 \%)$ & $58(83 \%)$ \\
\hline
\end{tabular}




\section{Conclusions}

The time challenges necessitate an enhanced professional component in the education of a technical professionals in a higher education institution. That is why we propose taking some of important recommendations of psychological and pedagogical theories as a basis. Namely, a teacher's assistance vector should be directed to support the student's activity; to create a certain pedagogical environment where a study case is perceived as a significant and predominant one by a student; to support orientation to positive emotions and a need for self-respect; to provide a psychologically comfortable educational environment for a person (including a decrease in the anxiety value). In this study our efforts were aimed at the achievement of the target function - the creation of a psychologically comfortable educational environment for a student. We applied certain pedagogical tools such as the transdisciplinary approach and blended learning.

In the context of the Russian Language and Business Communication course, we emphasized mini-research tasks intended to summarize knowledge, to identify the essentials and to fill up a ready-to-use scheme with unique content. These very tasks require transdisciplinary connections between the humanities and the non-humanities because special knowledge is combined with communicative skills, verbal persuasiveness and personal qualities (i.e., positive thinking, benevolence and reasonable self-esteem). In the implementation of the author's version of blended learning, the teacher's help was aimed at encouraging students to their own activity, to a preliminary whole understanding of the problem situation at a qualitative level, including due to increased attention to the imaginative presentation of the studied material for less skilled students.

A statistically significant difference in the examination grades in favor of the experimental groups, as well as a lower level of students' anxiety in them, were identified. We explain the latter, first of all, by the prompt assistance of teachers when students exceed a certain threshold of difficulties. When providing assistance, the teachers were guided by the ideas of transdisciplinarity and training on the background of positive emotions through the creation of psychologically comfortable conditions for the students educational activity. The criteria were the intensity of the educational activity and the level of anxiety acceptable to the individual. The hypothesis of sufficient effectiveness of the proposed objective function in the education is confirmed.

\section{Ethical Approval}

This article does not contain any studies with human participants or animals performed by any of the authors.

\section{Compliance with Ethical Standards}

\section{Conflict of Interest}

The authors declare that they have no conflict of interest.

\section{Informed Consent}

The students' survey was anonymous.

\section{REFERENCES}

[1] Andreev, V.V., Gibadulin, R. Ya., Prodanov, G. \& Zhdanov, R.I. (2017). Russian institute for advanced study as a new form of training of highly trained teaching staff. Integration of Education, 21(4), 623-636. (In Russ.). https://doi.org/10.15507/1991-9468.089.021.201704.623-6 36.

[2] Andreev, V.V., Gibadulin, R. Ya. \& Zhdanov, R.I. (2019) Formation of Transdisciplinary Approach to Scientific and Pedagogical Activity as a Basic Mission of the Institute for Advanced Study. Prepodavatel XXI vek, 2-1, 9-22. (In Russ.). Retrieved athttps://elibrary.ru/item.asp?id=3851258 4. Accessed 24 Jun 2020.

[3] Andreev, V.V., Gorbunov, V.I., Evdokimova, O.K. \& Rimondi, G. (2020a). Transdisciplinary approach to improving study motivation among university students of engineering specialties. Education and Self Development, 15(1). 21-37. https://doi.org/10.26907/esd15.1.03.

[4] Andreev, V.V., Gorbunov, V.I., Evdokimova, O.K., Nikitina, I.G. \& Trofimova, I.G. (2020b). Negative Aspects of the Use of Infocommunication Technologies by Undergraduate Students of Engineering Academic Programs in a Regional Russian University. Universal Journal of Educational Research, 8(3). 844-856. https://doi.org/10.13189/ujer.202 0.080315 .

[5] Bernstein, J.H. (2015). Transdisciplinarity: A review of its origins, development, and current issues. Journal of Research Practice, 11(1). Article R1. Retrieved at http://jrp.icaap.org/index.php/jrp/article/view/510/412. Accessed 24 Jun 2020.

[6] Chen, I.-C., Hwang, G.-J., Lai, C.-L. \& Wang, W.-C. (2020). From design to reflection: Effects of peer-scoring and comments on students' behavioral patterns and learning outcomes in musical theater performance. Computers \& Education, 150. 103856. https://doi.org/10.1016/j.compedu. 2020.103856.

[7] Clippinger, J.A. (1973). Toward a human psychology of personality. Journal of Religion and Health, 12. 241-258. https://doi.org/10.1007/BF01532830.

[8] Deci, E.L., \& Ryan, R.M. (2008). Self-determination theory: A macro theory of human motivation, development, and health. Canadian Psychology. Psychologie Canadienne, 49(3). 182-185. http://dx.doi.org/10.1037/a0012801.

[9] Duryagina, E.G. (2019). Study of subjective comfort of students within the examination period. Perspektivy nauki $i$ 
obrazovania - Perspectives of Science and Education, 37(1). 290-300. (In Russ.). https://doi.org/10.32744/pse.2019.1.21.

[10] Evdokimova, O.K., Gorbunov, V.I. \& Vasilyeva, L.N. (2017). On the problem of Training Scientific-Technical Intelligentsia at the University. I. Yakovlev Chuvash State Pedagogical University Bulletin, 3-2. 175-182. (In Russ.). Retrieved at https://elibrary.ru/item.asp?id=32274620. Accessed 24 Jun 2020.

[11] Evdokimova, O.K., Andreev, V.V. \& Gorbunov, V.I. (2019). Russian Language and Business Communications in the System of Training of Undergraduates in Engineering. $I$. Yakovlev Chuvash State Pedagogical University Bulletin, 5. 151-156. (In Russ.). Retrieved at https://elibrary.ru/item.as p?id=41563561. Accessed 24 Jun 2020.

[12] Gilbert, N.J. \& Driscoll, M.P. (2002). Collaborative knowledge building: A case study. Educational Technology Research and Development, 50. 59-79. https://doi.org/10.1 007/BF02504961.

[13] Gorbunov, V.I., Evdokimova, O.K. \& Mineev, A.I. (2017). Lifelong learning of humanitarian in the training system for bachelors in higher technical education. Studia Humanitatis, 1. (In Russ.). Retrieved at http://st-hum.ru/content/gorbuno v-vi-evdokimova-ok-mineev-ai-nepreryvnoe-gumanitarnoeobrazovanie-v-sisteme. Accessed 24 Jun 2020.

[14] Gorbunov, V.I. \& Evdokimova, O.K. (2018). Pedagogical conditions of teaching philological subjects to the bachelors in technical schools. Studia Humanitatis, 2. (In Russ.). Retrieved at http://st-hum.ru/content/gorbunov-vi-evdokim ova-ok-pedagogicheskie-usloviya-prepodavaniya-filologich eskih-disciplin. Accessed 24 Jun 2020.

[15] Gorbunov, V.I., Evdokimova, O.K., Rimondi, G. \& Andreev, V.V. (2019). Acquiring transdisciplinary knowledge by engineering students of Russian universities. Science for Education Today, 9(1). 172-187.http://dx.doi.org/10.15293 /2658-6762.1901.11.

[16] Cuesta Medina, L. (2018). Blended learning: Deficits and prospects in higher education. Australasian Journal of Educational Technology, 34(1).https://doi.org/10.14742/aje t.3100.

[17] Hanin, U.L. \& Spielberger, C.D. (1981). The Development and Validation of the Russian form of the State-Trait-Anxiety Inventory. In: Spielberger, C.D., Diaz-Guerrero, R. (eds) Cross-Cultural Anxiety, 2. Hemisphere Publishing Corporation.

[18] Imamgalieva, L.A. (2017). Sociological analysis of stress influence on students' behavior. Tambov University Review. Series Social Sciences, 3(2). 73-76. (in Russ.) Retrieved at https://www.elibrary.ru/item.asp?id=29273652. Accessed 24 Jun 2020.

[19] Iswadi, Syukri, M., Soewarno, Yulisman, H. \& Nurina, C.I.E. (2020). A systematic literature review of science teachers' TPACK related to STEM in developing a TPACK-STEM scale. Journal of Physics: Conference Series, 1460. 012105. https://doi.org/10.1088/1742-6596/1460/1/012105.

[20] Jang, S. \& Chen, K. (2010). From PCK to TPACK: Developing a Transformative Model for Pre-Service Science Teachers. Journal of Science Education and Technology, 19. 553-564. https://doi.org/10.1007/s10956-010-9222-y.

[21] Liu, Q., Geertshuis, S. \& Grainger, R. (2020). Understanding academics' adoption of learning technologies: A systematic review. Computers \& Education, 151. 103857. https://doi.org/10.1016/j.compedu.2020.103857.

[22] Mann, H.B. \& Whitney, D.R. (1947). On a Test of Whether One of Two Random Variables Is Stochastically Larger than the Other. Annals of Mathematical Statistics, 18(1). 50-60. http://dx.doi.org/10.1214/aoms/1177730491.

[23] Maslow, A.H. (1943). A theory of human motivation. Psychological Review, 50(4). 370-396. https://doi.org/10.1 037/h0054346.

[24] Pavlov, I.P. (1973). 20 Years of Experience of Objective Study of the Higher Nervous Activity (Behavior) of Animals. Nauka, Moscow. [In Russ.].

[25] Perez-Prado, A. \& Thirunarayanan, M.O. (2002). A qualitative comparison of online classroom-based sections of a course: Exploring student perspectives. Education Media International, 39(2). 195-202. https://doi.org/10.108 0/09523980210155343.

[26] Sanders, M. \& George, A. (2017). Viewing the changing world of educational technology from a different perspective: Present realities, past lessons, and future possibilities. Education and Information Technologies, 22. 2915-2933. https://doi.org/10.1007/s10639-017-9604-3.

[27] Santamaría-Bonfil, G., Ibáñez, M.B., Pérez-Ramírez, M., Arroyo-Figueroa, G. \& Martínez-Álvarez, F. (2020). Learning analytics for student modeling in virtual reality training systems: Lineworkers case. Computers \& Education, 151. 103871. https://doi.org/10.1016/j.compedu.2020.1038 71.

[28] Shim, S.H. (2008). A philosophical investigation of the role of teacher: A synthesis of Plato, Confucius, blubber and freire. Teaching and Teacher Education, 24(3). 515-535. https://doi.org/10.1016/j.tate.2007.09.014.

[29] Simonov, P.V. (2001). Lectures on Brain Operation: The Need-Informational Theory of Higher Nervous Activity. Nauka, Moscow. (In Russ.).

[30] Simonov, P.V. \& Yershov, P.M. (1991). Temperament, Character, Personality: Biobehavioral Concepts in Science, Art and Social Psychology. Philadelphia: Gordon and Breach Science Publishers.

[31] Sydeman, S. (2018). State-Trait Anxiety Inventory. In: Zeigler-Hill, V., Shackelford, T. (eds) Encyclopedia of Personality and Individual Differences. Springer, Cham. https://doi.org/10.1007/978-3-319-28099-8_950-1.

[32] Vasilieva, L.N., Volodina, E.V., Ilina, I.I. \& Andreev, V.V. (2020). Use of information and communication technologies (ICT) by university students: Evaluating the effectiveness for learning purposes. Science for Education Today, 10(2). 124-137. (In Russ.). http://dx.doi.org/10.15293/2658-6762. 2002.08

[33] Yalçın, H. \& Yayla, K. (2016). Scientometric analysis of the researches about technological pedagogical content knowledge and scholarly communication. Education and Science, 41(188). 291-307. https://doi.org/10.15390/EB.20 16.6746 .

[34] Zhao, J. (2013). Confucius as a Critical Educator: Towards Educational Thoughts of Confucius. Frontiers of Education in China, 8. 9-27. https://doi.org/10.1007/BF03396959. 